\title{
Microwave ablation combined with EGFR-TKIs versus only EGFR- TKIs in advanced NSCLC patients with EGFR-sensitive mutations
}

\author{
Zhigang Wei ${ }^{1}$, Xin Ye ${ }^{1}$, Xia Yang ${ }^{1}$, Aimin Zheng ${ }^{1}$, Guanghui Huang ${ }^{1}$, Wenhong $\mathrm{Li}^{1}$, \\ Jiao Wang ${ }^{1}$, Xiaoying Han ${ }^{1}$, Min Meng ${ }^{1}$ and Yang $\mathbf{N i}^{1}$ \\ ${ }^{1}$ Department of Oncology, Shandong Provincial Hospital Affiliated to Shandong University, Jinan 250021, Shandong Province, \\ China \\ Correspondence to: Xin Ye, email: yexintaian2014@163.com \\ Keywords: epidermal growth factor receptor, tyrosine kinase inhibitors, non-small cell lung cancer, microwave ablation, progression \\ free survival \\ Received: March 27, $2017 \quad$ Accepted: April 27, $2017 \quad$ Published: May 23, 2017 \\ Copyright: Wei et al. This is an open-access article distributed under the terms of the Creative Commons Attribution License 3.0 \\ (CC BY 3.0), which permits unrestricted use, distribution, and reproduction in any medium, provided the original author and source \\ are credited.
}

\section{ABSTRACT}

We conducted this retrospective study to investigate whether microwave ablation (MWA) of primary tumor sites plus epidermal growth factor receptor-tyrosine kinase inhibitors (EGFR-TKIs) could improve survival in advanced non small cell lung cancer (NSCLC) with EGFR mutations. MWA was conducted at the primary tumor sites, followed by EGFR-TKIs in the MWA plus EGFR-TKIs group. EGFR-TKIs were administered until disease progression or intolerable toxicity. The primary endpoint was progressionfree survival (PFS); secondary endpoints were overall survival (OS) and objective response rate (ORR). A total of 58 patients were recruited, including 34 in the MWA plus EGFR-TKIs group and 24 in the EGFR-TKIs group. No significant difference in ORR was observed with MWA treatment (61.8\% vs. 45.8\%, $p=0.230)$. Patients treated with MWA plus EGFR-TKIs failed to show superior survival in either PFS (13.2 months vs. 11.6 months, $p=0.640$ ) or OS (39.8 months vs. 20.4 months, $p=0.288$ ). MWA was not an independent prognostic factor for PFS or OS. MWA of primary tumor sites plus EGFRTKIs demonstrated no survival advantage compared with EGFR-TKIs alone in advanced NSCLC patients with EGFR sensitive mutations. MWA should not be recommended for unselected patients with EGFR-sensitive mutations.

\section{INTRODUCTION}

EGFR sensitive mutations, especially in-frame deletions in exon 19 and a point mutation in exon 21 (L858R), are present in 30-40\% of non-small cell lung cancer (NSCLC) patients and respond well to EGFRTKIs such as gefitinib and erlotinib. It is estimated that the ORR ranged from $60 \%$ to $83 \%$, with a median PFS of 8 to 11 months.[1-5]

Patients who respond to EGFR-TKIs will develop resistance eventually. Several mechanisms had been clarified; among them, an EGFR T790M mutation in exon 20 [6-9] and c-MET [10, 11] amplifications have been explored widely, and account for 50\% and $25 \%$ of all resistant mechanisms, respectively. What is more, PIK3CA mutation, [12] ERBB2 amplification, [13] HGF overexpression, [14] AXL activation, [15] epithelial-mesenchymal transition, and pathology type transformation, especially adenocarcinoma transformation into small cell lung cancer, have also been reported as causes of secondary resistance to EGFR-TKIs. [16-18]

According to the progression of EGFR-TKIs, secondary resistance can be clarified into three types: intracranial disease progression, development of asymptomatic oligometastases, and symptomatic disease progression. [19, 20] For the former two types, EGFR-TKIs could be continued after local therapy is administered. [21, 22]

For patients with intracranial progression, both whole-brain radiation therapy (WBRT) and stereotactic 
radiotherapy (SRT) could be treatment regimens. [20-22] For patients with oligometastases other than intracranial metastases, radiation therapy or thermal ablation could be applied. [20, 23-25] $\mathrm{Ni}$ et al. showed that patients with extra-central nervous system oligoprogressive disease had a median PFS of 8.8 months after microwave ablation (MWA), which was significantly different when compared with a transformation to platinum-based doublet chemotherapy. [25]

In previous studies, we verified that advanced NSCLC could benefit from a combination of MWA at primary tumor sites and platinum-based doublet chemotherapy. [26] What is more, a significant difference in PFS was also observed when compared with chemotherapy alone. [27] A recent phase II prospective, randomized, controlled clinical trial verified that local consolidative therapy with maintenance therapy for patients with three or fewer metastases from NSCLC (those who benefit from first-line systematic therapies) and demonstrated improved PFS when compared with maintenance therapy alone. The median PFS were 11.9 months and 3.9 months for consolidative plus maintenance therapy and maintenance therapy alone, respectively. [28] Local therapy including radiation and MWA in combination with systematic therapies improve survival in advanced NSCLC. Therefore, we conducted this retrospective study to determine whether advanced NSCLC patients with EGFR-sensitive mutations could benefit from MWA at primary tumor sites plus EGFRTKIs when compared with EGFR-TKIs alone.

\section{RESULTS}

\section{Patient characteristics}

From January 25, 2010 to May 19, 2016, 58 patients were enrolled, of whom 34 were in the MWA plus EGFR-TKIs group and 24 were in the EGFRTKIs group. In the MWA plus EGFR-TKIs group, 26 were women, 13 were aged 65 years or older, 33 had adenocarcinoma histology and an ECOG PS of 1, and 28 were nonsmokers. EGFR mutations included 18 19Del mutations and 19 exon 21 L858R mutations (including 3 patients with both 19Del mutations and L858R mutations). Nineteen patients were treated with EGFRTKIs as a first-line therapy and 15 patients were treated with EGFR-TKIs as a post-first-line therapy. The primary tumor size ranged from 0.8 to $9.0 \mathrm{~cm}$, with a mean of $3.7 \mathrm{~cm}$. Most patients (23 patients, 67.6\%) underwent ablation with two antennas and the typical ablation energy was $70 \mathrm{~W}$ (23 patients, 67.6\%). In the EGFRTKIs group, 13 were women aged 65 years or older, 23 had adenocarcinoma histology, 21 had an ECOG PS of 1 , and 17 were nonsmokers. EGFR mutations included 16 19Del mutations and 10 exon 21 L858R mutations (including two patients with both mutations). Sixteen patients were treated with EGFR-TKIs as a first-line therapy, and 8 patients were treated with EGFR-TKIs as a post-first-line therapy. The primary tumor size ranged from 1.6 to $8.8 \mathrm{~cm}$, with a mean of $3.9 \mathrm{~cm}$. Baseline characteristics of the enrolled patients are shown in detail in Table 1 .

\section{Response to MWA and EGFR-TKIs}

Complete ablation was achieved in 29 (85.3\%) of the 34 total patients in the MWA plus EGFR-TKIs group. The ORRs to EGFR-TKIs in the MWA plus EGFR-TKIs and EGFR-TKIs groups were 61.8\% (21/34) and 45.8\% $(11 / 24)(p=0.230)$, respectively.

\section{The correlation between MWA and survival}

Until November 19, 2016, with a median followup of 19.3 months (range, 6 to 52 months), 35 patients progressed, including 21 in the MWA plus EGFR-TKIs group and 14 in the EGFR-TKIs group. Sixteen patients died, of whom 9 and 7 were in the MWA plus EGFR-TKIs group and EGFR-TKIs group, respectively.

Patients treated with MWA plus EGFR-TKIs failed to show a survival advantage when compared with EGFR-TKIs only, with PFS durations of 13.2 months (95\% confidence interval [CI], 9.0-17.5 months) and 11.6 months (95\% CI, 4.7-18.5 months, $\mathrm{p}=0.640$ ), respectively (Figure 1). Patients with adenocarcinoma had longer PFS in comparison with non-adenocarcinoma NSCLC (13.2 months, 95\% CI, 9.8-16.6 months vs. 0.4 months, 95\% CI, 0.2-0.5 months, $\mathrm{p}=0.000)$. The response to EGFR-TKIs had a tendency to predict PFS (CR + PR vs. PD + SD, 14.6 months [95\% CI, 12.4-16.9 months] vs. 10.0 months $[95 \% \mathrm{CI}, 3.8-16.3$ months], $\mathrm{p}=0.067$ ) (Table 2).

OS was similar in both groups (MWA plus EGFR-TKIs group vs. EGFR-TKIs group, 39.8 months [95\% CI, 6.3-71.2 months] vs. 20.4 months [95\% CI, 11.3-29.5 months], $\mathrm{p}=0.288$; Figure 2). Patients with adenocarcinoma had better OS in comparison with nonadenocarcinoma NSCLC (16.2 months [95\% CI, 12.220.3 months] vs. 0.4 months [95\% CI, 0.2-0.5 months], $\mathrm{p}=0.000)$. Patients who achieved an ORR (CR + PR vs. PD + SD, 36.7 months [95\% CI, 28.2-45.3 months] vs. 25.2 months [95\% CI, 17.5-33.0 months], $\mathrm{p}=0.042$ ) and received treatment after progression with EGFRTKIs (treatment post-EGFR-TKIs vs. no treatment postEGFR-TKIs, 39.7 months [95\% CI, 5.5-74.0 months] vs. 11.4 months [95\% CI, 7.7-15.1 months], $\mathrm{p}=0.000$ ) also showed a survival advantage (Table 2).

In the multivariate analyses of PFS and OS, MWA was not a significant prognostic factor, and the corresponding p-values were 0.753 (hazard ratio [HR], 1.132 [95\% CI, 0.522-2.457]) (Table 3) and 0.976 (HR, 1.019 [95\% CI, 0.300-3.464]) (Table 4), respectively. 
Table 1: Baseline characteristics of 58 enrolled patients

\begin{tabular}{|c|c|c|c|c|c|}
\hline & & \multicolumn{2}{|c|}{ MWA+EGFR-TKIs } & \multicolumn{2}{|c|}{ EGFR-TKIs } \\
\hline & & Number & Percent $(\%)$ & Number & Percent(\%) \\
\hline \multicolumn{6}{|c|}{ Gender } \\
\hline & Male & 8 & 23.5 & 11 & 45.8 \\
\hline & Female & 26 & 76.5 & 13 & 54.2 \\
\hline \multirow[t]{3}{*}{ Age } & $58.9(29-85)$ & \multicolumn{4}{|c|}{$62.0(38-79)$} \\
\hline & $\geq 65$ & 13 & 38.2 & 11 & 45.8 \\
\hline & $<65$ & 21 & 61.8 & 13 & 54.2 \\
\hline \multicolumn{6}{|c|}{ Smoking history } \\
\hline & Non-smokers & 28 & 82.4 & 17 & 70.8 \\
\hline & Smokers & 6 & 17.6 & 7 & 29.2 \\
\hline \multicolumn{6}{|c|}{ ECOG } \\
\hline & 0 & 1 & 2.9 & 3 & 12.5 \\
\hline & 1 & 33 & 97.1 & 21 & 87.5 \\
\hline \multicolumn{6}{|c|}{ Pathology } \\
\hline & Adenocarcinoma & 33 & 97.1 & 23 & 95.8 \\
\hline & Non-adenocarcinoma & 1 & 2.9 & 1 & 4.2 \\
\hline \multicolumn{6}{|c|}{ Stage } \\
\hline & IIIB & 3 & 8.8 & 1 & 4.2 \\
\hline & IV & 31 & 91.2 & 23 & 95.8 \\
\hline \multicolumn{6}{|c|}{$\begin{array}{l}\text { EGFR sensitive } \\
\text { mutations }\end{array}$} \\
\hline & 19Del & $18^{*}$ & 39.4 & $16^{\#}$ & 66.7 \\
\hline & L858R & 16 & 60.6 & 8 & 33.3 \\
\hline \multicolumn{6}{|c|}{ Primary tumor size } \\
\hline & Mean & \multicolumn{2}{|c|}{3.7} & \multicolumn{2}{|c|}{3.9} \\
\hline & Range & \multicolumn{2}{|c|}{$0.8-9.0$} & \multicolumn{2}{|c|}{$1.6-8.8$} \\
\hline \multicolumn{6}{|c|}{ Primary tumor size } \\
\hline & $\geq 3.5 \mathrm{~cm}$ & 15 & 44.1 & 12 & 50.0 \\
\hline & $<3.5 \mathrm{~cm}$ & 19 & 55.9 & 12 & 50.0 \\
\hline \multicolumn{6}{|c|}{ Primary tumor site } \\
\hline & Right lung & 20 & 58.8 & 15 & 62.5 \\
\hline & Left lung & 14 & 41.2 & 9 & 37.5 \\
\hline \multicolumn{6}{|c|}{ Primary tumor site } \\
\hline & Upper and middle lobe & 12 & 35.3 & 21 & 87.5 \\
\hline & Lower lobe & 22 & 64.7 & 3 & 12.5 \\
\hline \multicolumn{6}{|c|}{ Power of MWA } \\
\hline & $60 \mathrm{~W}$ & 11 & 32.4 & & \\
\hline & $70 w$ & 23 & 67.6 & & \\
\hline & & & & & (Continued) \\
\hline
\end{tabular}




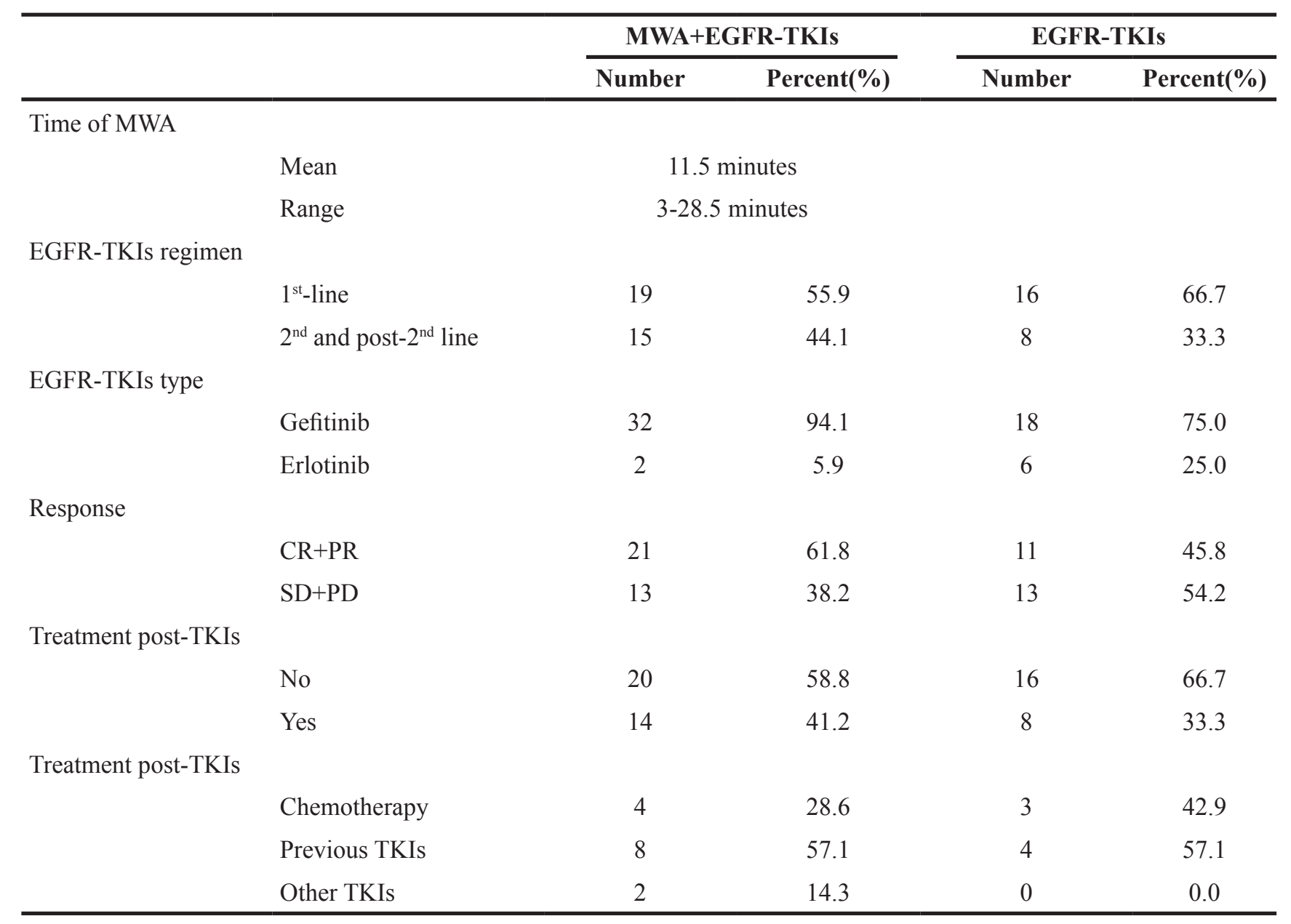

*Three patients had both 19Del and L858R mutations.

\#Two patients had both 19Del and L858R mutations.

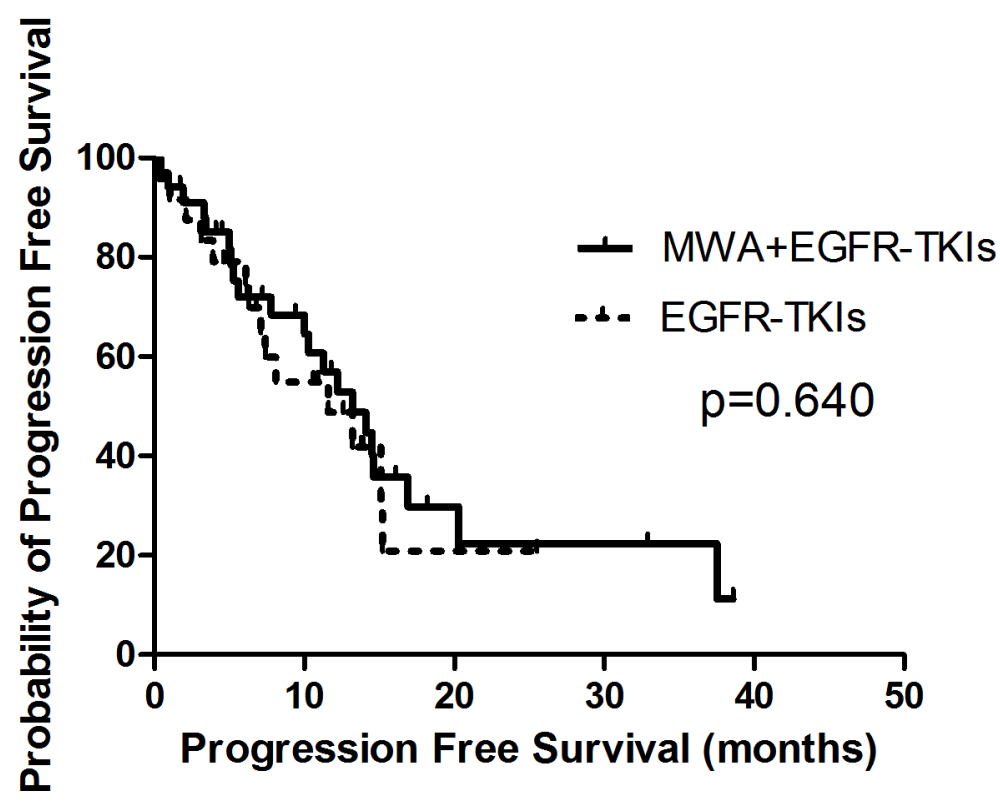

Figure 1: Kaplan-Meier estimates of PFS in 58 patients. The median PFS of patients treated with MWA plus EGFR-TKIs was 13.2 months (95\%CI, 9.0-17.5 months), and those received EGFR-TKIs was 11.6 months (95\%CI, 4.7-18.5 months). 
Table 2: Univariant analyses of progression free survival and overall survival

\begin{tabular}{|c|c|c|c|c|c|c|c|}
\hline & & PFS(ms) & $95 \% \mathrm{CI}$ & $\mathbf{p}$ & $\mathrm{OS}(\mathrm{ms})$ & $95 \% \mathrm{CI}$ & $\mathrm{p}$ \\
\hline \multirow[t]{3}{*}{ Gender } & & & & 0.053 & & & 0.140 \\
\hline & Male & 7.4 & $4.2-10.7$ & & 21.4 & $12.4-30.4$ & \\
\hline & Female & 14.1 & $12.1-16.1$ & & 39.8 & $13.8-65.7$ & \\
\hline \multirow[t]{3}{*}{ Age } & & & & 0.631 & & & 0.490 \\
\hline & $\geq 65$ & 14.1 & $9.8-18.4$ & & 23.5 & $18.0-29.0$ & \\
\hline & $<65$ & 12.2 & $7.9-16.4$ & & 32.5 & $24.4-40.6$ & \\
\hline \multirow[t]{3}{*}{ Smoking history } & & & & 0.403 & & & 0.540 \\
\hline & Non-smokers & 13.2 & $10.2-16.1$ & & 31.8 & $24.6-38.9$ & \\
\hline & Smokers & 10.3 & $5.3-23.3$ & & 23.1 & $25.1-38.0$ & \\
\hline \multirow[t]{3}{*}{ ECOG } & & & & 0.373 & & & 0.720 \\
\hline & 0 & 20.1 & $7.4-32.7$ & & 28.2 & $19.9-36.5$ & \\
\hline & 1 & 14.8 & $10.7-18.8$ & & 31.1 & $29.9-42.6$ & \\
\hline \multirow[t]{3}{*}{ Pathology } & & & & 0.000 & & & 0.000 \\
\hline & Adenocarcinoma & 13.2 & $9.8-16.6$ & & 16.2 & $12.2-20.3$ & \\
\hline & $\begin{array}{l}\text { Non- } \\
\text { adenocarcinoma }\end{array}$ & 0.4 & $0.2-0.5$ & & 0.4 & $0.2-0.5$ & \\
\hline \multirow[t]{3}{*}{ Stage } & & & & 0.692 & & & 0.938 \\
\hline & IIIB & 10.0 & $4.1-16.0$ & & 25.6 & $13.6-37.6$ & \\
\hline & IV & 13.1 & $10.2-16.1$ & & 31.2 & $24.5-37.9$ & \\
\hline \multirow[t]{3}{*}{ EGFR mutation } & & & & 0.599 & & & 0.385 \\
\hline & 19Del & 11.6 & $6.2-17.0$ & & 36.3 & $29.9-41.6$ & \\
\hline & L858R & 13.2 & $10.6-15.7$ & & 27.7 & $19.9-35.5$ & \\
\hline \multirow[t]{3}{*}{ MWA } & & & & 0.640 & & & 0.288 \\
\hline & No & 11.6 & $4.7-18.5$ & & 20.4 & $11.3-29.5$ & \\
\hline & Yes & 13.2 & $9.0-17.5$ & & 39.8 & $8.3-71.2$ & \\
\hline \multirow[t]{3}{*}{$\begin{array}{l}\text { EGFR-TKI } \\
\text { regimen }\end{array}$} & & & & 0.501 & & & 0.975 \\
\hline & $1^{\text {st }}$-line & 14.1 & $10.1-18.2$ & & 30.7 & $23.0-38.4$ & \\
\hline & $\begin{array}{l}2^{\text {nd }} \text { and post }-2^{\text {nd }} \\
\text { line }\end{array}$ & 12.2 & $3.6-20.8$ & & 31.1 & $22.0-40.3$ & \\
\hline \multirow[t]{3}{*}{ EGFR-TKI type } & & & & 0.981 & & & 0.936 \\
\hline & Gefitinib & 13.2 & $10.3-16.1$ & & 30.3 & $23.4-37.2$ & \\
\hline & Erlotinib & 7.1 & $0.0-26.8$ & & 34.3 & $21.4-47.2$ & \\
\hline \multirow[t]{3}{*}{ Response } & & & & 0.067 & & & 0.042 \\
\hline & $\mathrm{CR}+\mathrm{PR}$ & 14.6 & $12.4-16.9$ & & 36.7 & $28.2-45.3$ & \\
\hline & $\mathrm{SD}+\mathrm{PD}$ & 10.0 & $3.8-16.3$ & & 25.2 & $17.5-33.0$ & \\
\hline \multirow[t]{3}{*}{$\begin{array}{l}\text { Treatment post- } \\
\text { TKIs }\end{array}$} & & & & 0.147 & & & \\
\hline & No & 5.0 & $3.1-7.0$ & & 11.4 & $7.7-15.1$ & \\
\hline & Yes & 7.8 & $2.9-12.7$ & & 39.7 & $5.5-74.0$ & \\
\hline
\end{tabular}


Table 3: Multivariant analyses of progression free survival

\begin{tabular}{lcccc}
\hline & \multicolumn{5}{c}{$\mathbf{9 5 \% C I}$} & $\mathbf{p}$ \\
\cline { 2 - 5 } & HR & Lower & Upper & 0.127 \\
\hline Gender & 1.996 & 0.823 & 4.842 & 0.545 \\
ECOG & 1.610 & 0.344 & 7.534 & 0.967 \\
Smoking history & 0.981 & 0.397 & 2.425 & 0.753 \\
MWA & 1.132 & 0.522 & 2.457 & 0.206 \\
Response & 0.619 & 0.295 & 1.301 & \\
\hline
\end{tabular}

Table 4: Multivariant analyses of progression free survival

\begin{tabular}{lcccc}
\hline & \multicolumn{5}{c}{$\mathbf{9 5 \% \mathbf { C I }}$} \\
\cline { 2 - 5 } & HR & Lower & Upper & $\mathbf{p}$ \\
\hline Gender & 2.082 & 0.622 & 6.966 & 0.234 \\
Age & 1.564 & 0.538 & 4.552 & 0.412 \\
EGFR mutations & 0.478 & 0.155 & 1.473 & 0.199 \\
MWA & 1.019 & 0.300 & 3.464 & 0.976 \\
Response & 0.280 & 0.087 & 0.900 & 0.033 \\
Post-EGFR-TKIs & 0.404 & 0.121 & 1.343 & 0.139 \\
\hline
\end{tabular}

In order to explore the correlation between the number of tumor sites and the survival benefit of MWA, we divided patients into two groups, those with three or fewer tumor metastases and those with more than three tumor sites other than the primary tumor in advanced. No differences were observed in either group in PFS or OS (Figures 3-6). For patients with more than three tumor metastases, the median PFS were 11.3 months (95\% CI, 3.1-22.9 months) and 15.1 months (95\% CI, 8.1-22.2 months) $(\mathrm{p}=0.874)$ (Figure 3) for the MWA plus EGFR-TKIs group and the EGFRTKIs group, respectively, and the corresponding OS were 28.4 months (95\% CI, 18.1-38.6 months) and 18.2 months (95\% CI, 15.1-21.2 months) ( $\mathrm{p}=0.859)$,

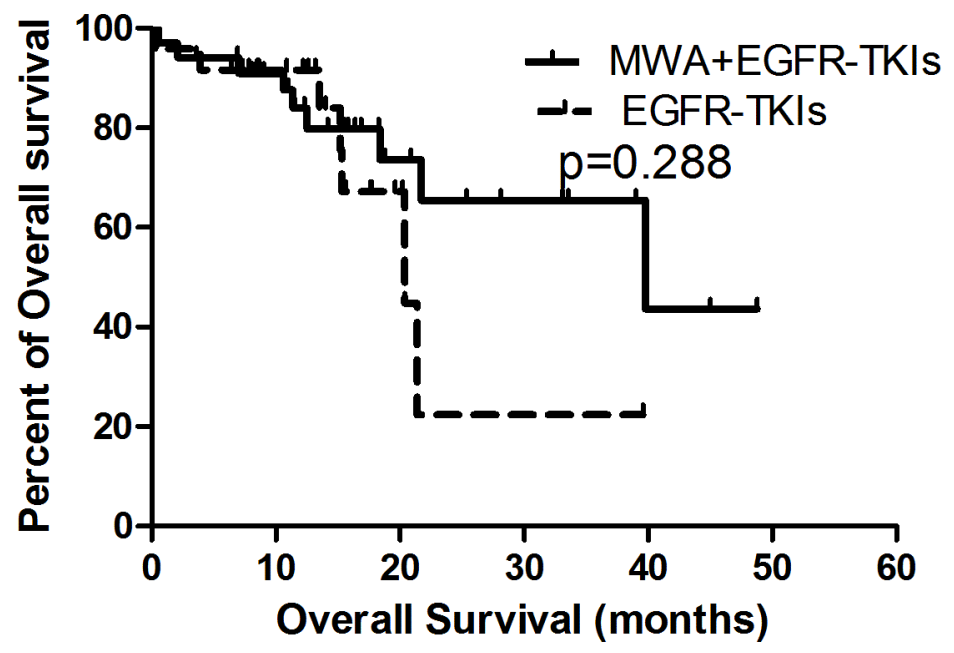

Figure 2: Kaplan-Meier estimates of OS in 58 patients. The median OS of patients treated with MWA plus EGFR-TKIs was 39.8 months (95\%CI, 6.3-71.2 months), and those received EGFR-TKIs was 20.4 months (95\%CI, 11.3-29.5 months). 
respectively (Figure 4). For patients with three or fewer tumor metastases, the median PFS were 13.2 months (95\% CI, 9.1-17.4 months) and 7.4 months (95\% CI, 5.7-9.1 months) $(\mathrm{p}=0.545)$ (Figure 5) for the MWA plus EGFR-TKIs group and the EGFR-TKIs group, respectively, and the corresponding OS were 38.0 months (95\% CI, 28.8-47.2 months) and 23.3 months (95\% CI, 12.2-34.3 months), respectively $(\mathrm{p}=0.212)$ (Figure 6).

\section{DISCUSSION}

EGFR-TKIs remain the standard of care for advanced NSCLC with EGFR-sensitive mutations and show a dramatic improvement in PFS. [1-5] However, all patients will develop resistance ultimately, even those who achieve complete or incomplete remission. [6-18]

Multiple studies explored the following treatment strategy after the failure of EGFR-TKIs. Based on the

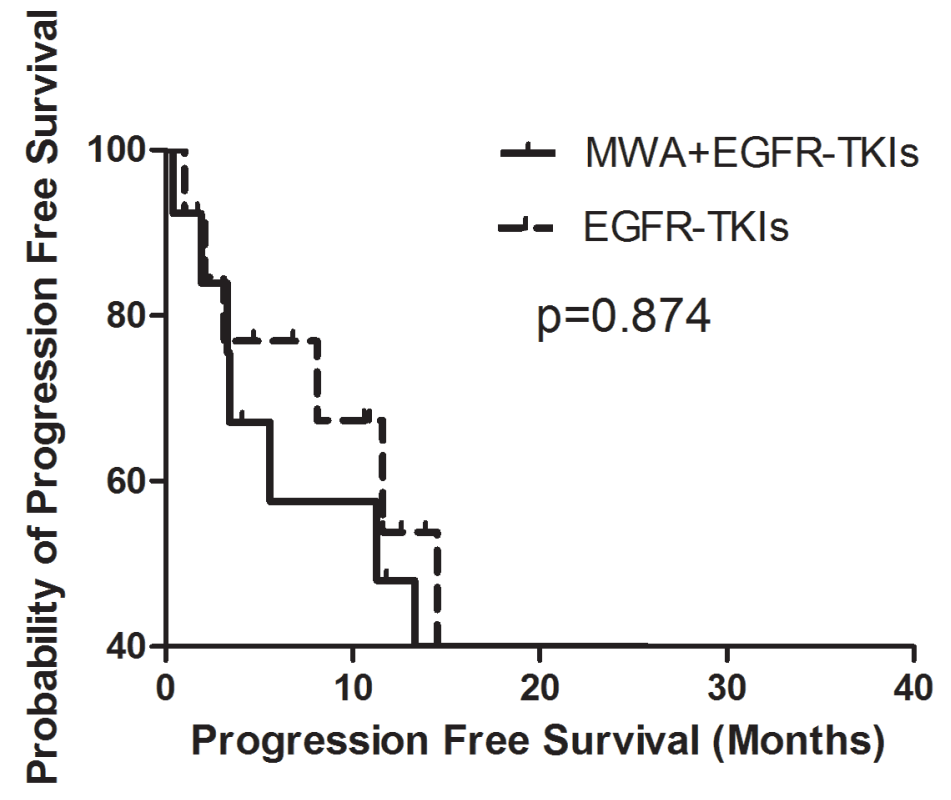

Figure 3: Kaplan-Meier estimates of PFS in 26 patients with metastatic sites more than 3. The median PFS of patients treated with MWA plus EGFR-TKIs was 11.3 months (95\%CI, 3.1-22.9 months), and those received EGFR-TKIs was 15.1 months (95\%CI, 8.1-22.2 months).

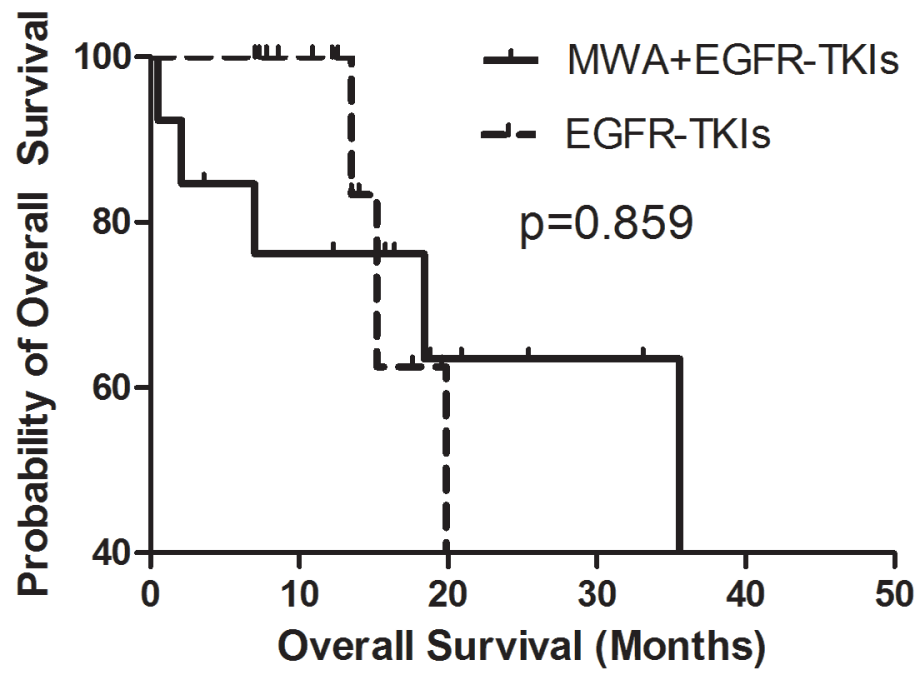

Figure 4: Kaplan-Meier estimates of OS in 26 patients with metastatic sites more than 3. The median OS of patients treated with MWA plus EGFR-TKIs was 28.4 months (95\%CI, 18.1-38.6 months), and those received EGFR-TKIs was 18.2 months (95\%CI, 15.1-21.2 months). 
progression models, the therapies varied. [19, 20] For those with brain progression, SBRT or SRT was the first choice, and the EGFR-TKIs were continued. [20-22] For patients with local disease progression, local treatments including radiation or thermal ablation in combination with previous EGFR-TKIs were recommended [20, 23, 24, 33-35]. However, chemotherapy and transfer to a third EGFR-TKI were treatment options for those with widespread metastasis.
We firstly explored whether the combination of MWA at primary tumor sites and EGFR-TKIs could improve PFS when compared with EGFR-TKIs alone for advanced NSCLC with EGFR-sensitive mutations. No significant difference was observed in either PFS or OS in univariate and multivariate analyses, indicating that MWA and EGFR-TKIs did not have a synergistic effect, which was different from radiation plus EGFRTKIs. Welsh et al. [21] showed that patients with EGFR-

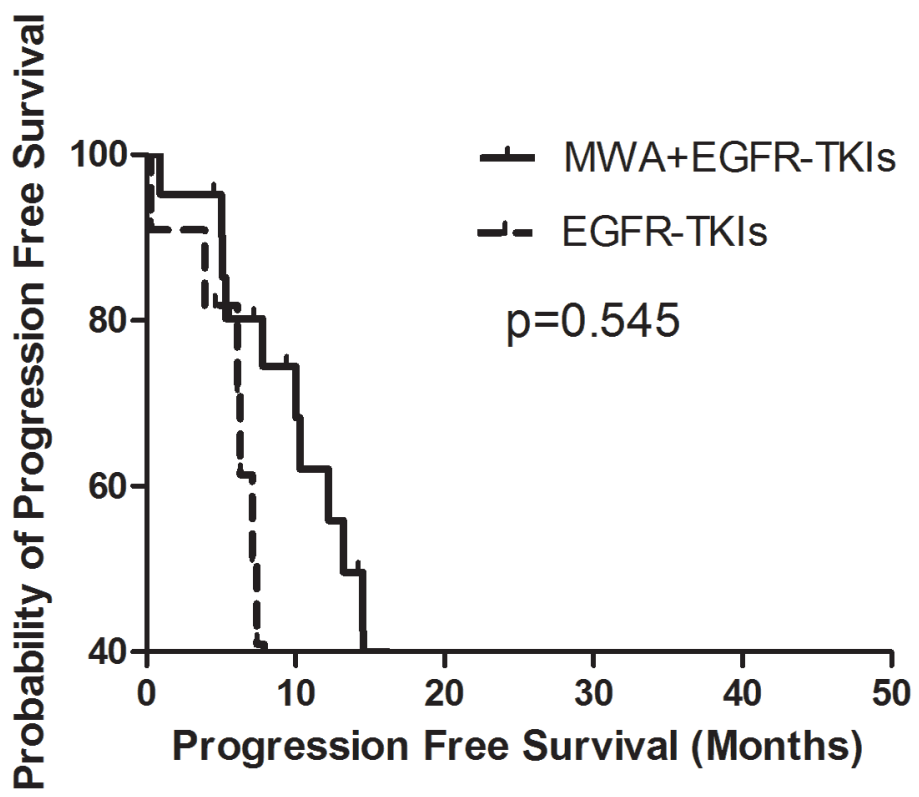

Figure 5: Kaplan-Meier estimates of PFS in 32 patients with metastatic sites of 3 or fewer. The median PFS of patients treated with MWA plus EGFR-TKIs was 13.2 months (95\%CI, 9.1-17.4 months), and those received EGFR-TKIs was 7.4 months (95\%CI, 5.7-9.1 months) .

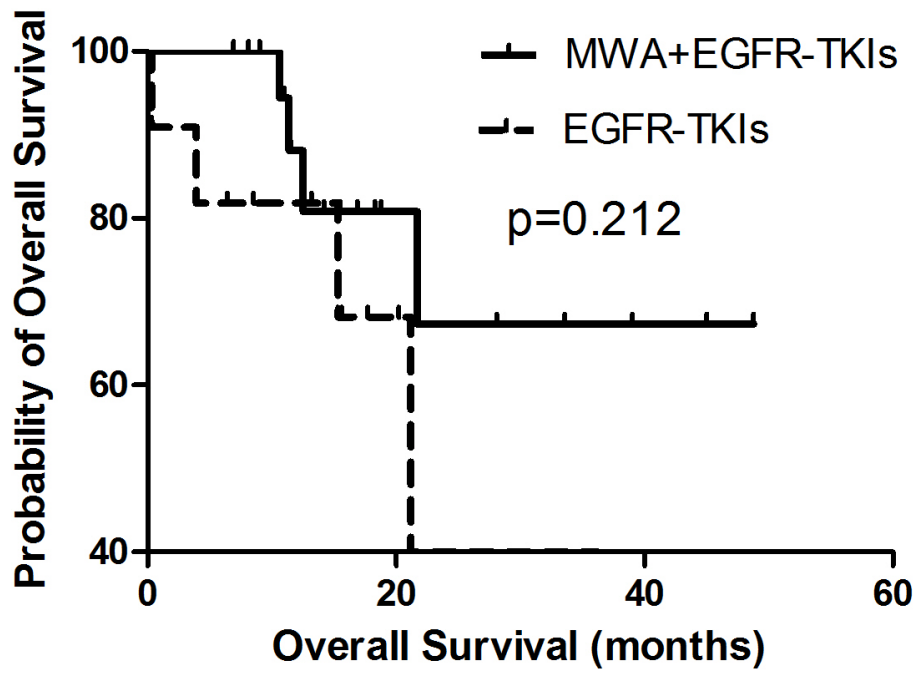

Figure 6: Kaplan-Meier estimates of OS in 32 patients with metastatic sites of 3 or fewer. The median OS of patients treated with MWA plus EGFR-TKIs was 38.0 months (95\%CI, 28.8-47.2 months), and those received EGFR-TKIs was 23.3 months (95\%CI, 12.2-34.3 months). 
sensitive mutations and brain metastases had superior survival and ORRs when treated with EGFR-TKIs and SBRT. William et al. [22] verified that the median OS and intracranial PFS were longer in the group treated with RT upfront compared with the group treated with EGFR-TKIs upfront. What is more, Zeng et al. [36] showed that concomitant administration of gefitinib and WBRT was found to result in higher treatment response and disease control rates in patients with EGFR-sensitive mutations and NSCLC brain metastases compared with gefitinib alone. Hong et al. [33] found that in NSCLC patients with EGFR-sensitive mutations and skeletal metastasis progression, EGFR-TKIs continued in combination with radiation after treatment with EGFR-TKIs and disease progression resulted in a PFS of 5.6 to 8.0 months. Isolated bone failure without systemic disease progression is associated with better survival when treated with continuation of EGFR-TKIs plus local radiation. [24] Studies verified that EGFRTKIs could modulate the radiation response. [37, 38] When combined with radiation, EGFR-TKIs promote a further reduction in the S-phase fraction, resulting in an accumulation of cells in G1 and G2. [37] What is more, TKIs enhance the induction of apoptosis, inhibit EGFR autophosphorylation and Rad51 expression, and improve radiosensitivity. [37] EGFR inhibition led to pronounced cellular senescence of irradiated cells. Moreover, cellular senescence is a prominent mechanism in radiosensitization. The senescence and radiosensitization were linked to an increase in residual radiation-induced DNA double-strand breaks irrespective of $\mathrm{p} 53 / \mathrm{p} 16$ status. [39]

To explore the correlation between the number of tumor sites and the survival benefit of MWA, we divided patients into two groups, those with three or fewer tumor metastases and those with more than three tumor sites other than the primary tumor in advanced. No differences were observed in either group in PFS or OS. Gomez et al. [28] showed that advanced NSCLC patients without driver mutations after systematic treatments of platinum-based doublet chemotherapy and patients with driver mutations after EGFR-TKIs or ALK inhibitors had longer PFS when treated with consolidated treatments followed by maintenance treatments compared with maintenance treatments alone. An 8-month PFS was observed, which was significantly different. However, the study was restricted to those with oligometastases, which was defined as no more than three tumor sites. Chiang et al. [34] also showed that radical palliative thoracic RT was safe and might be beneficial for primary lung lesions in patients with metastatic NSCLC and controlled extrathoracic diseases. The median OS, PFS after RT, and OS after RT were 50 months, 15 months, and 18 months, respectively. Qin et al. [35] reported that when patients who responded to EGFR-TKIs received EGFR-TKIs and local radiofrequency hyperthermia, the PFS and OS were 22 months and 26 months, respectively. The difference in PFS indicated that local treatments, which did not focus on all tumor sites, did not have a survival advantage for patients with EGFR-sensitive mutations treated with MWA plus EGFR-TKIs.

In conclusion, for advanced NSCLC patients with EGFR-sensitive mutations, MWA at the primary tumor sites plus EGFR-TKIs failed to show a survival advantage when compared with EGFR-TKIs alone.

\section{MATERIALS AND METHODS}

\section{Patient characteristics}

Patients with pathologically verified advanced NSCLC and EGFR-sensitive mutations, i.e., an exon 19 deletion or exon 21 L858R point mutation, were recruited. Other inclusion criteria included an age no less than 18 years; Eastern Cooperative Oncology Group Performance Status (ECOG PS) of 0 to 1; no local therapy at primary tumor sites, such as radiation, radiofrequency ablation (RFA), or I125 radioactive particle implantation; and adequate bone marrow, hepatic, and renal function. The exclusion criteria were as follows: serious issues with pulmonary and cardiovascular function such that MWA could not be risked; previous treatment with EGFR-TKIs or local therapies for primary tumors; baseline interstitial lung disease; cerebral hemorrhage, cerebral infarction, or coronary heart disease, especially unstable angina or myocardial infarction during the previous 6 months; and anti-platelet or anti-necrosis treatments during the past 1 week.

The study was approved by the ethics committee of Shandong Provincial Hospital affiliated with Shandong University prior to study enrollment. Written informed consent was obtained from all enrolled patients.

\section{MWA procedure}

All patients allocated to the MWA plus EGFRTKIs group received MWA at primary tumor sites under computed tomography guidance. The procedure has been detailed in our previous reports. [25, 26, 29]

\section{EGFR mutation testing}

DNA was extracted from 4- $\mu$ m formalin-fixedand parrffin-embedded,(FFPE) tumor slides by using the QIAamp DNA FFPE Tissue Kit (Qiagen, Germany) according to the manufacturer's instructions. The EGFR mutation testing procedure was described in detail in our previous study. [30] A classic S-curve and a $\mathrm{Ct}$ value $>30$ were considered to be a positive result, indicating the presence of a mutation. 


\section{EGFR-TKIs}

Patients received $250 \mathrm{mg}$ oral gefitinib or $150 \mathrm{mg}$ erlotinib once daily until disease progression or intolerable toxicity. The interval between MWA and EGFR-TKIs therapy was 1 week.

\section{The follow-up and response evaluation}

MWA follow-up was performed every month for 3 months post-ablation and at 3-month intervals thereafter. The response to EGFR-TKIs was evaluated 1 month later and then at 2-month intervals.

The response to MWA was assessed according to a Chinese expert consensus [31]. The response to EGFRTKIs was conducted according to the Response Evaluation Criteria in Solid Tumors (RECIST) version 1.1 [32].

\section{Statistical analyses}

SPSS version 17.0 (USA) was applied for statistical analyses. The primary endpoint was PFS; the secondary endpoint was overall survival (OS). PFS was calculated from the date of MWA to disease progression for both primary tumor sites and other tumor sites or death for those treated with MWA plus EGFR-TKIs. For patients who received EGFR-TKIs only, PFS was calculated from the start of treatment with EGFR-TKIs to disease progression or death. OS was calculated from the diagnosis of NSCLC to death from any cause. Both PFS and OS were analyzed using Kaplan-Meier univariate analyses and Cox regression multivariate analyses. Factors with p-values less than 0.5 in the univariate analyses besides MWA were examined in the Cox regression multivariate analyses. Chi-square test was used to test the correlation between the response to EGFR-TKIs and the treatment regimens. All tests were two-sided, and p-values less than 0.05 were considered to represent a significant difference.

\section{ACKNOWLEDGMENTS}

The scientific guarantor of this publication is Xin Ye. The authors of this manuscript declare no relationships with any companies, whose products or services may be related to the subject matter of the article. This study has received funding by Shandong Province medical and health science and technology development projects (2014WS0346). Zhigang Wei has significant statistical expertise. Institutional Review Board approval was obtained. Written informed consent was obtained from all subjects (patients) in this study. No study subjects or cohorts have been previously reported. This retrospective observational study was performed at one institution.

\section{CONFLICTS OF INTEREST}

No conflicts of interest exists.

\section{REFERENCES}

1. Mok TS, Wu YL, Thongprasert S, Yang CH, Chu DT, Saijo N, Sunpaweravong P, Han B, Margono B, Ichinose Y, Nishiwaki Y, Ohe Y, Yang JJ, et al. Gefitinib or carboplatinpaclitaxel in pulmonary adenocarcinoma. N Engl J Med. 2009; 361: 947-957.

2. Rosell R, Moran T, Queralt C, Porta R, Cardenal F, Camps C, Majem M, Lopez-Vivanco G, Isla D, Provencio M, Insa A, Massuti B, Gonzalez-Larriba JL, et al. Screening for epidermal growth factor receptor mutations in lung cancer. N Engl J Med. 2009; 361: 958-967.

3. Maemondo M, Inoue A, Kobayashi K, Sugawara S, Oizumi S, Isobe H, Gemma A, Harada M, Yoshizawa H, Kinoshita I, Fujita Y, Okinaga S, Hirano H, et al. Gefitinib or chemotherapy for non-small-cell lung cancer with mutated EGFR. N Engl J Med. 2010; 362: 2380-2388.

4. Mitsudomi T, Morita S, Yatabe Y, Negoro S, Okamoto I, Tsurutani J, Seto T, Satouchi M, Tada H, Hirashima T, Asami K, Katakami N, Takada M, et al. Gefitinib versus cisplatin plus docetaxel in patients with non-small-cell lung cancer harbouring mutations of the epidermal growth factor receptor (WJTOG3405): an open label, randomised phase 3 trial. Lancet Oncol. 2010; 11: 121-128.

5. Zhou C, Wu YL, Chen G, Feng J, Liu XQ, Wang C, Zhang S, Wang J, Zhou S, Ren S, Lu S, Zhang L, Hu C, et al. Erlotinib versus chemotherapy as first-line treatment for patients with advanced EGFR mutation-positive non-smallcell lung cancer (OPTIMAL, CTONG-0802): a multicentre, open-label, randomised, phase 3 study. Lancet Oncol.

2011; 12: 735-742.

6. Kobayashi S, Boggon TJ, Dayaram T, Jänne PA, Kocher O, Meyerson M, Johnson BE, Eck MJ, Tenen DG, Halmos B. EGFR mutation and resistance of non-small-cell lung cancer to gefitinib. N Engl J Med. 2005; 352: 786-792.

7. Pao W, Miller VA, Politi KA, Riely GJ, Somwar R, Zakowski MF, Kris MG, Varmus H. Acquired resistance of lung adenocarcinomas to gefitinib or erlotinib is associated with a second mutation in the EGFR kinase domain. PLoS Med. 2005; 2: e73.

8. Sequist LV, Waltman BA, Dias-Santagata D, Digumarthy S, Turke AB, Fidias P, Bergethon K, Shaw AT, Gettinger S, Cosper AK, Akhavanfard S, Heist RS, Temel J, et al. Genotypic and histological evolution of lung cancers acquiring resistance to EGFR inhibitors. Sci Transl Med. 2011; 3: $75 \mathrm{ra} 26$.

9. Arcila ME, Oxnard GR, Nafa K, Riely GJ, Solomon SB, Zakowski MF, Kris MG, Pao W, Miller VA, Ladanyi M. Rebiopsy of lung cancer patients with acquired resistance to EGFR inhibitors and enhanced detection of the T790M 
mutation using a locked nucleic acid-based assay. Clin Cancer Res. 2011; 17: 1169-1180.

10. Engelman JA, Zejnullahu K, Mitsudomi T, Song Y, Hyland C, Park JO, Lindeman N, Gale CM, Zhao X, Christensen J, Kosaka T, Holmes AJ, Rogers AM, et al. MET amplification leads to gefitinib resistance in lung cancer by activating ERBB3 signaling. Science. 2007; 316: 1039-1043.

11. Bean J, Brennan C, Shih JY, Riely G, Viale A, Wang L, Chitale D, Motoi N, Szoke J, Broderick S, Balak M, Chang WC, Yu CJ, et al. MET amplification occurs with or without T790M mutations in EGFR mutant lung tumors with acquired resistance to gefitinib or erlotinib. Proc Natl Acad Sci U S A. 2007; 104: 20932-20937.

12. Fujii A, Harada T, Iwama E, Ota K, Furuyama K, Ijichi K, Okamoto T, Okamoto I, Takayama K, Nakanishi Y. Hypermethylation of the $\mathrm{CpG}$ dinucleotide in epidermal growth factor receptor codon 790: implications for a mutational hotspot leading to the T790M mutation in nonsmall-cell lung cancer.Cancer Genet. 2015; 208: 271-278.

13. Takezawa K, Pirazzoli V, Arcila ME, Nebhan CA, Song X, de Stanchina E, Ohashi K, Janjigian YY, Spitzler PJ, Melnick MA, Riely GJ, Kris MG, Miller VA, et al. HER2 amplification: a potential mechanism of acquired resistance to EGFR inhibition in EGFR-mutant lung cancers that lack the second-site EGFRT790M mutation. Cancer Discov. 2012; 2: 922-933.

14. Yano S, Takeuchi S, Nakagawa T, Yamada T. Ligandtriggered resistance to molecular targeted drugs in lung cancer: roles of hepatocyte growth factor and epidermal growth factor receptor ligands. Cancer Sci. 2012; 103: 1189-1194.

15. Zhang Z, Lee JC, Lin L, Olivas V, Au V, LaFramboise T, Abdel-Rahman M, Wang X, Levine AD, Rho JK, Choi YJ, Choi CM, Kim SW, et al. Activation of the AXL kinase causes resistance to EGFR-targeted therapy in lung cancer. Nat Genet. 2012; 44: 852-860.

16. Kim J, Vasu VT, Mishra R, Singleton KR, Yoo M, Leach SM, Farias-Hesson E, Mason RJ, Kang J, Ramamoorthy P, Kern JA, Heasley LE, Finigan JH, et al. Bioinformaticsdriven discovery of rational combination for overcoming EGFR-mutant lung cancer resistance to EGFR therapy. Bioinformatics. 2014; 30: 2393-2398.

17. Yu HA, Arcila ME, Rekhtman N, Sima CS, Zakowski MF, Pao W, Kris MG, Miller VA, Ladanyi M, Riely GJ. Analysis of tumour specimens at the time of acquired resistance to EGFR-TKI therapy in 155 patients with EGFR-mutant lung cancers. Clin Cancer Res. 2013; 19: 2240-2247.

18. Suda K, Tomizawa K, Fujii M, Murakami H, Osada H, Maehara Y, Yatabe Y, Sekido Y, Mitsudomi T. Epithelial to mesenchymal transition in an epidermal growth factor receptor-mutant lung cancer cell line with acquired resistance to erlotinib. J Thorac Oncol. 2011; 6: 1152-1161.

19. Matikas A, Mistriotis D, Georgoulias V, Kotsakis A. Current and future approaches in the management of non-small-cell lung cancer patients with resistance to EGFR TKIs. Clin Lung Cancer. 2015; 16: 252-261.

20. Weickhardt AJ, Scheier B, Burke JM, Gan G, Lu X, Bunn PA Jr, Aisner DL, Gaspar LE, Kavanagh BD, Doebele RC, Camidge DR. Local ablative therapy of oligoprogressive disease prolongs disease control by tyrosine kinase inhibitors in oncogene-addicted non-small-cell lung cancer. J Thorac Oncol. 2012; 7: 1807-1814.

21. Welsh JW, Komaki R, Amini A, Munsell MF, Unger W, Allen PK, Chang JY, Wefel JS, McGovern SL, Garland LL, Chen SS, Holt J, Liao Z, et al. Phase II trial of erlotinib plus concurrent whole-brain radiation therapy for patients with brain metastases from non-small-cell lung cancer. J Clin Oncol. 2013; 31: 895-902.

22. Magnuson WJ, Yeung JT, Guillod PD, Gettinger SN, Yu JB, Chiang VL. Impact of deferring radiation therapy in patients with epidermal growth factor receptor mutant none small cell lung cancer who develop brain metastases. Int J Radiat Oncol Biol Phys .2016; 95: 673-679.

23. Yu HA, Sima CS, Huang J, Solomon SB, Rimner A, Paik P, Pietanza MC, Azzoli CG, Rizvi NA, Krug LM, Miller VA, Kris MG, Riely GJ. Local therapy with continued EGFR tyrosine kinase inhibitor therapy as a treatment strategy in EGFR-mutant advanced lung cancers that have developed acquired resistance to EGFR tyrosine kinase inhibitors. J Thorac Oncol. 2013; 8: 346-351.

24. Hwang JA, Lee JY, Kim WS, Song JS, Rho JK, Choi $\mathrm{CM}$, Lee JC. Clinical implications of isolated bone failure without systemic disease progression during EGFR-TKI treatment. Clin Lung Cancer. 2016; 17: 573-580.

25. Ni Y, Bi J, Ye X, Fan W, Yu G, Yang X, Huang G, Li W, Wang J, Han X, Ni X, Wei Z, Han M, et al. Local microwave ablation with continued EGFR tyrosine kinase inhibitor as a treatment strategy in advanced non-small cell lung cancers that developed extra-central nervous system oligoprogressive disease during EGFR tyrosine kinase inhibitor treatment: a pilot study. Medicine (Baltimore). 2016; 95: e3998.

26. Wei Z, Ye X, Yang X, Zheng A, Huang G, Li W, Ni X, Wang J, Han X. Microwave ablation in combination with chemotherapy for the treatment of advanced non-small cell lung cancer. Cardiovasc Intervent Radiol. 2015; 38: 135-142.

27. Wei Z, Ye X, Yang X, Huang G, Li W, Wang J, Han $X$. Microwave ablation plus chemotherapy improved progression-free survival of advanced non-small cell lung cancer compared to chemotherapy alone. Med Oncol. 2015; 32: 464.

28. Gomez DR, Blumenschein GR Jr, Lee JJ, Hernandez M, Ye R, Camidge DR, Doebele RC, Skoulidis F, Gaspar LE, Gibbons DL, Karam JA, Kavanagh BD, Tang C, et al. Local consolidative therapy versus maintenance therapy or observation for patients with oligometastatic non-smallcell lung cancer without progression after first-line systemic 
therapy: a multicentre, randomised, controlled, phase 2 study. Lancet Oncol. 2016; 17: 1672-1682.

29. Yang X, Ye X, Zheng A, Huang G, Ni X, Wang J, Han X, Li W, Wei Z. Percutaneous microwave ablation of stage I medically inoperable non-small cell lung cancer: clinical evaluation of 47 cases. J Surg Oncol. 2014; 110: 758-763.

30. Wei Z, Ye X, Yang X, Huang G, Li W, Wang J, Han X, Meng M, Ni Y. Advanced non small cell lung cancer: response to microwave ablation and EGFR status. Eur Radiol. 2017; 27: 1685-1694.

31. Ye X, Fan W, Chen JH, Feng WJ, Gu SZ, Han Y, Huang GH, Lei GY, Li XG, Li YL, Li ZJ, Lin ZY, Liu BD, et al. Chinese expert consensus workshop report: guidelines for thermal ablation of primary and metastatic lung tumors. Thoracic Cancer. 2015; 6: 112-121.

32. Eisenhauer EA, Therasse P, Bogaerts J, Schwartz LH, Sargent D, Ford R, Dancey J, Arbuck S, Gwyther S, Mooney M, Rubinstein L, Shankar L, Dodd L, et al. New response evaluation criteria in solid tumours: revised RECIST guideline (version 1.1). Eur J Cancer. 2009; 45: 228-247.

33. Hong SH, Kim YS, Lee JE, Kim IH, Kim SJ, Han D, Yoo IeR, Chung YG, Kim YH, Lee KY, Kang JH. Clinical characteristics and continued epidermal growth factor receptor (EGFR) tyrosine kinase inhibitor administration in EGFR-mutated non-small cell lung cancer with skeletal metastasis.Cancer Res Treat. 2016; 48: 1110-1119.

34. Chiang Y, Yang JC, Hsu FM, Chen YH, Shih JY, Lin ZZ, Lan KH, Cheng AL, Kuo SH. The response, outcome and toxicity of aggressive palliative thoracic radiotherapy for metastatic non-small cell lung cancer patients with controlled extrathoracic diseases. PLoS One. 2015; 10: e0145936.

35. Qin Y, Sun Y, Liu Y, Luo Y, Zhu J. Pilot study of radiofrequency hyperthermia in combination with gefitinib in gefitinib-effective patients with advanced NSCLC.Thorac Cancer. 2016; 7: 422-427.

36. Zeng YD, Zhang L, Liao H, Liang Y, Xu F, Liu JL, Dinglin $\mathrm{XX}$, Chen LK. Gefitinib alone or with concomitant whole brain radiotherapy for patients with brain metastasis from non-small-cell lung cancer: a retrospective study. Asian Pac J Cancer Prev. 2012; 13: 909-914.

37. Chinnaiyan P, Huang S, Vallabhaneni G, Armstrong E, Varambally S, Tomlins SA, Chinnaiyan AM, Harari PM. Mechanisms of enhanced radiation response following epidermal growth factor receptor signaling inhibition by erlotinib (Tarceva). Cancer Res. 2005; 65: 3328-3335.

38. Das AK, Chen BP, Story MD, Sato M, Minna JD, Chen DJ, Nirodi CS.Somatic mutations in the tyrosine kinase domain of epidermal growth factor receptor (EGFR) abrogate EGFR-mediated radioprotection in non-small cell lung carcinoma. Cancer Res. 2007; 67: 5267-5274.

39. Wang M, Morsbach F, Sander D, Gheorghiu L, Nanda A, Benes C, Kriegs M, Krause M, Dikomey E, Baumann M, Dahm-Daphi J, Settleman J, Willers H. EGF receptor inhibition radiosensitizes NSCLC cells by inducing senescence in cells sustaining DNA double-strand breaks. Cancer Res. 2011; 1: 6261-6269. 